Article

\title{
"He Who Sees Does Not Desire to Imagine": The Shifting Role of Art and Aesthetic Observation in Medieval Franciscan Theological Discourse in the Fourteenth Century
}

\author{
Oleg Bychkov \\ Theology Department, Saint Bonaventure University, St Bonaventure, NY 14778, USA; obychkov@sbu.edu \\ Received: 13 February 2019; Accepted: 13 March 2019; Published: 18 March 2019

\begin{abstract}
In the thirteenth century, following Neoplatonic and Patristic trends, art and aesthetic experience were still treated as symbolic, as "vestiges" or "echoes" of the divine that lead us to it. However, in the early fourteenth century, attitudes to concrete sensory/aesthetic experience begin to shift and theologians adopted the model of concrete phenomenal observation of sensory experience. Concrete sensory-aesthetic experience is endowed with a much higher value: seeing something is not the same as imagining it, recalling it, or thinking about it. This new approach results in some heterodox views about our phenomenal experience and debates about the exact status of "intentional" (phenomenal) appearance. These debates lead to profound observations about the nature of aesthetic-sensory experience of art objects and a re-evaluation of the status of the artistic image, which is now seen as much more than the platonic "copy of a copy". In other words, starting with the fourteenth century, theologians start to pay attention to concrete aesthetic (sensory) experience and use their observations to make conclusions about various cognitive and perceptual issues that could be relevant to a discussion of the divine. That is, quite separately from theoretical theological observations, art and aesthetic experience now provide independent approaches to the divine or spiritual via the experience of aesthetic wonder as a starting point. It is now our concrete experience of sensory and aesthetic objects that starts the train of thought, at times leading to some unorthodox conclusions that contradict the doctrine (such as the skeptical point of view). The intellectual shift in treating sensory and artistic objects in the fourteenth century invites some parallels with the current discussions of the experience of aesthetic wonder in "post-secular" thought.
\end{abstract}

Keywords: concepts: image; art; aesthetic; post-secular; wonder; Franciscan theology; intentionality; sensory experience

A brief look at the cultural history of humanity, from Australian aboriginals, who, through their unbroken tribal tradition, provide a snapshot of humanity as it was 50,000 years ago ${ }^{1}$, to nineteenth century Europe, suggests that religion, in its broadest sense as human belief in a reality beyond this one, and the arts, in their broadest sense as human aesthetic expression, have been forever linked. While the arts and aesthetic expression have maintained their important position in human culture, in recent centuries, religion has been losing ground to a secular mentality, and the arts have been partly divorced from religion. Since the time of European Romanticism and its echoes in North America in the early nineteenth century, the arts and aesthetic experience have been increasingly presented as a new religion or a substitute for religion. In the past few decades, the idea of a post-secular mentality

1 As an example, see the use of art by Australian Aboriginals in the National Geographic documentary Australia's Aborigines (NGHT, Inc., 2009). 
was floated in Anglo-American intellectual circles². Dissatisfied with the disenchantment of secular life, with its reductionist scientific picture of the world-with no God, no self ${ }^{3}$, and sometimes not even consciousness in the picture, and with the determinist view that leaves no space for free will or any purpose to our existence-the post-secular person craves a re-enchantment of the world 4 . The post-secular sentiment rides the boundary between the secular and the religious, often capitalizing on phenomena that are part of everybody's secular experience and yet are somehow suggestive of something going beyond it, and thus quasi-religious. One of such phenomena is wonder or amazement in the face of the world-either its sheer existence or its intricate patterns ${ }^{5}$. The arts and aesthetic experience, once again, play a major role in eliciting the emotion of wonder, as the arts have traditionally made us aware of both the sheer fact of the existence of objects, and of beautiful patterns that suggest a regular organization of the universe based on eternal and universal laws, which are revealed to us by means of our reaction of wonder and aesthetic pleasure. In view of the developing post-secular mentality, and the quasi-religious role of the arts in it, the question is, if one looks at the history of human appreciation of the arts, when exactly the arts and aesthetic experience begin to be used autonomously or independently from theoretical theological observations to provide independent approaches to the divine or spiritual via the experience of aesthetic wonder as a starting point. The essay will focus on one specific period in medieval intellectual history, the early to mid-fourteenth century, when theological debates on the nature of sensory perception between several prominent Franciscan theologians, such as Peter Aureol (d. 1322), William Ockham (d. 1347), Walter Chatton (d. 1343), and Adam Wodeham (d. 1358), seem to shift the paradigm of how the arts are treated in a religious context and herald a new approach to secular art and secular experiences of art under a theological angle.

\section{Toward a New Theory of the Image}

In European scholarship, both Western and Eastern, much has been attributed to the supposed "secularization" of religious art in Western Christianity after Carolingian theologians reject both its sacred status and the iconoclastic position in the Libri Carolini (790) and at the Frankfurt Council (794): the position that supposedly both protected the use of art in religion and at the same time liberated it from its sacred-symbolic role and its rigid traditional iconographic types employed by Eastern Christianity ${ }^{6}$. However, all evidence, both iconic and textual, suggests the contrary. First, medieval Western Christian art pretty much sticks to rigid iconographic types up to the mid or even late thirteenth century. One needs only a quick look at religious images from that era, e.g., at newly created images of St. Francis, such as the Bardi dossal, to notice that they look very much like Eastern icons. ${ }^{7}$ What is more important is that the theology of the image until the mid and even late thirteenth century remains very traditional. Let us take as an example the Franciscan order, which develops a theology that is most sensitive to aesthetic issues. (The reasons for this are Francis's own sensitivity to the

2 e.g., see Levine 2011; Warner et al. 2010.

3 This is a rather common, if shocking, view held by many contemporary neuroscientists and neuropsychologists, a typical example being David Eagleman, see: Eagleman 2011, and Eagleman 2017, pp. 75-106.

4 See Taylor 2011.

5 See Costa 2011. On the concept of wonder further see: Attfield 2018; Willmott 2018; Vasalou 2015.

6 For the supposed impact of the Libri Carolini and the Frankfurt Council on Western religious art, see: Quenot 1996, pp. 72-83; Sendler 1999, pp. 28-30. An immense literature in languages other than English exists on the practice of following traditional iconographic types in the Eastern Orthodox tradition, which is often called canonicity or canon. The practice can be documented textually in great detail starting with the sixteenth century, but elements of it are reflected in texts as early as the seventh century, and the pictorial evidence is obvious throughout the history of Orthodoxy. In English, see: Quenot 1996, pp. 66-72; Sendler 1999, pp. 19-21; Evdokimov 1996, pp. 213-17.

7 There are many historical reasons for that, such as that many Eastern iconographers fled to Italy during iconclastic persecutions, and that Franciscans specifically during the period of the Crusades had icon workshops in the Holy Land and the Latin Empire of Constantinople, which were directly impacted by local iconographers. However, this does not explain the persistence of rigid iconographic types in the West, since Western Christians supposedly had a choice not to follow these practices or not to employ Eastern-style iconographers. 
material world and the Augustinian and Dionysian sources of early Franciscan theology). Franciscan theology engages a number of aesthetic issues, such as the beauty of the universe and of Christ as early as in the so-called Sum of Theology of Alexander of Hales. ${ }^{8}$ Bonaventure is probably the most aesthetic of early Franciscan theologians. ${ }^{9}$ However, Bonaventure's schema in the mid to late thirteenth century still reflects the traditional view of art formulated in Christian Patristic theology. His position on the role of images in churches is reminiscent of John Damascene's standard opinion against iconoclasts: they serve as "visual scriptures" for the illiterate, excite affection, and assist memory; the honor paid to the picture goes back to the prototype. His theology elaborates somewhat on this standard view, but still goes no further than professing the symbolic role of artistic images: like other material things, they are echoes and vestiges of the divine. From Augustine he borrows the idea of the transcending movement of the mind, which begins with perceiving patterns in physical reality by using one's aesthetic sense and ends with a realization of their eternal God-like nature. From contemporary perspectivists he borrows the theory of the sensory form (species) of a material thing in the mind and applies it to the second person of the Trinity. Just as the sensory species, which travels through various levels of reality, up to our intellect, and points back to its source, Christ as form-beauty (species), as the perfect likeness of the Father, points back to the Father. ${ }^{10}$

It seems that in order to see any real change in attitudes toward art and sensory-aesthetic experience in Western Christianity one needs to fast-forward to the fourteenth century. Once again, what follows is based on the Franciscan theological tradition. Following Peter John Olivi and John Duns Scotus's emphases on the role of concrete sensory experience in constructing cognitive and epistemological sections of theology ${ }^{11}$, Franciscan theologians of the fourteenth century abandon the religious-symbolic view of art and natural beauty and begin to pay attention to specific sensory experiences—-which are equally available to secularly-minded individuals—and the way they allow one to fine-tune one's cognitive theory. One sees a rising number of references to sensory experience, a frequent use of aesthetic comparisons that involve concrete aesthetic experiences, including those of art objects (and not just symbolic interpretations of art or abstract examples), and a development of fine theological points based on these concrete experiences, and not stemming from preconceived theological notions about art and aesthetics. It seems that to Franciscan theologians from the fourteenth century, sensory and aesthetic experiences were the source of a genuine intellectual wonder that triggered further insights into the nature of our perception of what we call "reality": an important preliminary step in any medieval commentary on the Sentences prior to embarking on an exploration of the divine.

\section{The Importance of Sensory Experience}

As part of the preliminary discussion of the range and possibilities of human cognition, including the possibility of cognition of the divine, theologians in the fourteenth century faced a major epistemological hurdle-and it is precisely sensory and aesthetic experience that was called upon in Franciscan theology to clear it. The problem they faced was that the reliability of sensory perception and phenomenal experience was threatened by the 63rd proposition of the condemnations of 1277 , which rejected the thesis that "God cannot produce the effect of a secondary cause without the secondary cause itself"12. The position implied that all of our sensory and phenomenal experiences at least in principle could exist without any real things standing behind them, because God can simulate them for our mind. Several major Franciscan theologians, such as Peter Aureol, William

8 See Bychkov 2010, pp. 271, 301-2.

9 See Bychkov 2013; Bychkov 2010, pp. 268-321.

10 In addition to Bychkov (2013) see Sent. III, dist. 9, art. 1, qu. 2 (III, 202-5). Bonaventure's works are cited according to the "great" Quaracchi edition.

11 See Olivi's Sent. II, q. 57, in Olivi 1924. On Scotus, see Bychkov 2014.

12 See Denifle and Châtelain 1889, p. 547. 
Ockham, Walter Chatton, and Adam Wodeham, rely on sensory and aesthetic experience to argue about this issue. Several major positions develop on the issue of reliability of sensory experience between these four theologians. Aureol insists that some special mode of being is at play, which he calls variously "intentional", "apparent", "conspicuous" and so on, to account for the phenomenal appearances of things to our minds that seemingly can exist without any "real" things standing behind them-not only under God's hypothetical influence but even naturally. Common proofs brought forth in support of this position are cases when we have phenomenal experiences of things that are not actually there, as when we experience sensory illusions, afterimages, and hallucinations. For example, according to Wodeham, who discusses this opinion (even though it is not his own), it could happen that "some [visual] elements of a currently present thing might be visible that mimic the shape of a rabbit or a castle when other elements are out of sight" and we actually take it for a rabbit or a castle $^{13}$. Just about everybody else except Aureol denies the existence of this special mode of being, but their positions on the status of phenomenal appearance vary ${ }^{14}$. While Ockham is a typical direct realist who simply postulates that unless there is some impediment, we perceive real things as they are in reality, and our sensory perception is absolutely trustworthy, most theologians, such as Chatton and Wodeham, assume a moderate stance: there is no intermediate being between our mind and real things, but our phenomenal perception of them can be affected in various ways by the conditions of perception and its interpretation by our mental faculties, which accounts for illusions and afterimages. Thus, our sensory perception can be trusted only for the most part, although this is sufficient for practical purposes.

In order to prove their points in the midst of this heated debate, all sides rely heavily on sensory experience. Thus Peter Aureol, defending his claim that even things that are not physically present can appear phenomenally to our mind, speaks of the "way of experience, to which one must adhere more than to any whatsoever logical arguments, because science begins with experience," and the "indication of truth in speech is its correspondence with things that are perceived by the senses"15. Although Ockham is radically opposed to Aureol's idea of apparent being, he also values actual sensory experience and its tight connection to our intellectual processes, except, according to him, it proves the opposite, that the process of sensory perception is direct and unmediated by any apparent being ${ }^{16}$.

Chatton and Wodeham have, perhaps, the most extensive comments on the importance of sensory experience. Chatton's direct realist position, against that of Aureol, is that our phenomenal experience of objects of sensory perception is not some special kind of being, but the act of sensory perception itself, e.g., vision ${ }^{17}$. Chatton, as most of his contemporaries, is concerned with the certitude of the information delivered by the senses, because "we have maximal certitude about objects of sensory perception by virtue of the fact that we experience our sensory perceptions, through which objects of sensation appear to us as present"18. In his opinion, Aureol's model of apparent being inserts some sort of an intermediary between the object and the faculty of sensory perception and introduces skeptical doubt. In his defense of the role of sensory perception, Chatton goes further than his Franciscan predecessors and even denies the need for intellective intuitive cognition: a type of intellectual cognition that makes us aware of the immediate presence of objects of sense perception or mental activities. Most Franciscan theologians prior to Chatton, such as Scotus or Ockham, include this sort of cognition in their cognitive

13 Lectura secunda 1, prol., qu. 3, par. 8, in Wodeham 1990, p. 82.

14 The literature on the debate about "intentional being" is enormous, and there is no space in this essay to discuss the issue or even to cite all the literature. A concise account of the issue itself and of the complex palette of positions that develop around it in Franciscan thought in the fourteenth century is given in Bychkov 2018.

15 Aureol, Scriptum 1, Prooemium, Sectio Secunda, C., Resp., art. 3, n. 81, in Aureoli 1956, p. 198.

16 Cf. Ockham, Ord. 1, prol., q. 1, a. 1, in Ockham 1967, p. 38.10-11.

17 See Chatton, Rep. et Lect. 1, prol., q. 2, a. 2: "it creates less of a difficulty to concede that the 'objective being' of an extramental thing is the very act of vision," in Chatton 1989, p. 88.65-70; "the very cognition [of an extramental thing] can be called a 'being' of this object. This denomination does not concern anything internal [to the thing]. When it is used, what it means is that a thing is cognized; all it means is that this cognition is present in the soul" (Chatton 1989, p. 89.83-6). 
theory ${ }^{19}$. According to Chatton however, sensory intuitive cognition is all we need to verify the existence of an extramental object; this position, of course, radically increases the importance of sensory perception ${ }^{20}$. And yet, assuming a more moderate position compared to that of Ockham, Chatton does admit the fact of residual sensations, such as afterimages after having seen a bright object, even though he attempts to explain them away without using Aureol's model of apparent being ${ }^{21}$.

While Chatton's concession implies (whether he likes the consequence or not) that sensory intuitive cognition provides no basis for certainty, Wodeham opposes even Chatton's concession. He contends that in the realm of nature, sensory intuitive cognition certifies the existence of extramental objects. His only concession, following the condemnation of 1277, is that God can simulate any sensory experience without extramental thing ${ }^{22}$. Reason and experience correct misleading appearances of "non-existent" things mentioned in Aureol's examples, and the senses ordinarily can be trusted, except under very unusual circumstances, such as divine interference. Like Chatton, Wodeham opposes Scotus and Ockham and denies the necessity of intellective intuitive cognition (notitia incomplexa intuitiva) that is different from sensation, claiming that sensory cognition is sufficient to assent to an object of sensory perception (res sensibilis) ${ }^{23}$. Wodeham's attempt to eliminate intellective intuitive cognition, of course, is aimed at eliminating uncertainty in sensory perception. The problem of how "physical" sensory material gets into a purely "spiritual" intellect remains unresolved in Aristotle and Aquinas ${ }^{24}$. However, if one argues for the unity of sensory and intellectual capacities, presenting them more like shades of the same rather than sharply divided, sensory cognition can account for the certainty of perception, as there is no need to "spiritualize" it in order to transfer it to the intellect. If there is only one perceptive power, there is no need to prove the reality of the extramental world to the intellect, and skepticism is eliminated. In fact, of course, neither side of the debate about the status of phenomenal appearances (Aureol vs. Ockham/Chatton/Wodeham) ultimately eliminates skeptical doubt. However, while attempting to do so, curiously, both sides elevate the importance of sensory experience to a much higher level.

19 Cf. Scotus, Ord. IV, d. 45, qq. 2-3, and Ockham, Ord. 1, prol., q. 1.

20 Chatton, Rep. et Lect. 1, prol., q. 2, a. 4 (Chatton 1989, p. 112.204-11): "it seems that in this life the soul naturally does not have any intuitive intellection [of sensibles], because exterior sensations are sufficient to it to cause any whatsoever assent to things signified by contingent propositions. Indeed, when the soul forms the compound proposition 'whiteness exists', while at the same time experiencing a sensory vision of whiteness, everything else having been circumscribed, the result is an assent to the thing that is signified by the contingent compound proposition 'whiteness exists'. Therefore, one ought not posit there any other [type of] intuitive cognition in respect to this [object] except for sensory vision."

21 Chatton, Rep. et Lect. 1, prol., q. 2, a. 2 (Chatton 1989, p. 91.150-58; cf. Chatton 1989, p. 95.255-66): “Indeed, on some occasions the vision that has been previously caused has a tendency to remain for some time after the object of vision has gone away. This is because the intense [visual] species, which immediately causes vision, remains for some time after the object of vision has gone away, on account of the intensity of this [visual] species. However, no vision ever has a tendency to be naturally caused or preserved for a long time without the presence of the object of vision... for neither is the [visual] species itself naturally caused nor remains for a long time without the thing of which it is the species....". Otherwise, Chatton cautions, we would not have any certitude about sensory objects caused by natural causes. These arguments, of course, do not make a good case against Aureol, because one still needs to account for where that residual image is, and Chatton fails to account at all for hallucinations. In fact, Chatton himself admits that even short residual sensations put a dent into his position by conceding that at the time when that residual vision remains, while the object has disappeared, "there is no certitude" (Chatton 1989, p. 92.175ff).

22 Wodeham, Lectura secunda 1, prol., qu. 2, par. 4-5 (Wodeham 1990, pp. 40-41).

23 Wodeham, Lectura secunda 1, prol., qu. 1, par. 2 (Wodeham 1990, pp. 9-10): intellective intuitive cognition would be required in order in ensure an "evident judgment about the existence of a sensory thing" and its contingent conditions. However, as things stand, it is not required, "because when something white is demonstrably visible, we accept an evident and certain assent of the intellect, by which it judges that this [sensory thing] exists." This judgment does not need any other simple intuitive knowledge apart from this "sensory vision," unless this vision is obscure or imperfect. This statement is repeated almost verbatim in Wodeham, Lectura secunda 1, prol., qu. 1, par. 4 (Wodeham 1990, p. 13), and is paraphrased in par. 11 (Wodeham 1990, p. 25). In fact, our sensory experience is so cognitive in nature that we routinely apply the language of intellection to it: "All our sensations are immediately received in the intellect and are acts of the intellect, although properly speaking no sensation is intellection.... Therefore all statements such as the following are true, even though only accidentally: 'the intellect knows something white by sensory vision' or '[the intellect knows] a sound by means of hearing'" (par. 5 [Wodeham 1990, p. 15]).

24 See Bychkov 2015. 
Fascination with sensory experience in the fourteenth century, in fact, runs so high that Franciscan theologians often place it not only above the faculty of the imagination but even above the faculty of reason ${ }^{25}$. Thus Aureol, despite the main thrust of his theory of apparent being that presents all phenomenal experience, even under natural conditions, as mental simulation (to use a modern term) and thus seems to put the certainty of sensory perception into question, still values sensory or aesthetic experience (which he calls "intuitive knowledge") higher than the imagination or ideation, because it provides a more direct and vivid contact with the object of perception. Aureol, unlike Chatton or Wodeham, tries to defend the existence of intuitive intellective cognition in the mind. His line of argument proceeds as follows: if he can prove that intuitive cognition generally is superior to other forms of cognition, then the intellective faculty must include it. Aureol proves this by drawing an analogy between the operation of the intellective and sensory faculties. In the sensory faculty, the role of intuitive cognition falls to direct sensory perception, while the role of abstractive cognition to the imagination. Aureol's comparison between sensory perception and imagination turns into a kind of apologia of sensory perception: an intuitive or sensory knowledge of an object, such as a rose, is more desirable, delightful, clear, and certain than imagining the same object:

For it is clear that intuitive [sensory] knowledge is more noble than the knowledge gained through the imagination [i.e., abstractive], on many accounts. First, because it is desirable. For a person who imagines something desires to see it; however, he who sees [something] does not desire to imagine [it]. Second, because it is more delightful. For it is more delightful to see a rose or a thing one loves than to imagine it. Third, because it is more clear. For the person who imagines a certain thing still experiences himself to remain somehow in the dark as regards this thing; however, he who sees [something, experiences] the clarity of knowledge in every respect. Fourth, because it is more certain. For vision is experiential knowledge, and imagination is not. And therefore [Aristotle] in Bk. 2 of On the Soul attributes truth to the senses and deception and proneness to error to the imagination. Fifth, it follows from the above that it is more perfect and ultimate, for it unites [the one who perceives] with the object [of perception] most perfectly and ultimately. ${ }^{26}$

Chatton seconds this evaluation: seeing or experiencing a thing in a sensory way is very different from just knowing or thinking about it. Chatton in this case argues against Ockham: while Ockham claims that science is about compound propositions about things (complexum), Chatton and Wodeham argue that science is about things themselves (in the case of Wodeham, more precisely, about both things themselves and propositions about them, which he calls "significative compounds"). Wodeham agrees with Chatton, and to prove the point he borrows his distinction between conclusions by demonstration and from experience. The two propositions (by demonstration and from experience) are not similar, even though they signify one and the same thing, but are "of a different nature":

although he who actually sees a [real] thing would not necessarily form an abstractive concept [of it]... nevertheless, if he were to form it... that concept would be of a different nature compared to a concept that one forms when one does not see [this] thing. Otherwise already in this life we would form propositions about God that are as evident as those that the blessed form in the next. Now a conclusion that is a result of a [logical] demonstration is put together out of concepts that are formed without having seen the thing that causes [this

25 The trend is apparent already in Scotus, whose thought triggers many subsequent discussions. For example, according to Scotus, the reason that the sacraments are accompanied by sensory signs is that "we seek and desire more avidly that, which is known to us more clearly, for all our acquisition of knowledge in this earthly life originates with sensation; therefore, in order that we may seek and desire grace more intensely and fervently, it must be presented to us under a sensory sign" (Reportatio IV-A, dist. 26-28, Resp., Civitas Vaticana, bibl. apost., cod. vat. lat. 883, f. 286ra).

26 Aureol, Scriptum 1, Prooemium, Sectio Secunda, C., Resp., art. 4, n. 117 (Aureoli 1956, p. 208). 
proposition]. However, a proposition that one forms after having experienced the thing is put together out of such concepts as the thing causes by means of vision. ${ }^{27}$

\section{Intentional Objects and Images}

Heated debates about apparent or intentional being between Aureol and his opponents simply bring into relief one more time that mysterious identity between real things and their phenomenal stand-ins that we perceive every day. Even Aureol's opponents acknowledge the capacity of phenomenal appearances in mental experience to create a vivid feeling that what we perceive are things "out there" in their "outerness". To use philosophical terminology, they create an "ontological commitment". In Aureol's words, "intellection seems to terminate at the [real] thing, and our gaze to observe the thing itself, and to glance over it as over an object that is [currently] in our presence", e.g., when we say "I understand, look at, or observe a rose" 28 .

However, the most interesting observation for aesthetics that comes out of these debates against Aureol's model of intentionality is that it is not only phenomenal appearances of perceived things that can create this feeling of outerness and identity between phenomenal appearances and things that are perceived as extramental, but also phenomenal appearances of perceived images of things, such as their artistic representations. Thus Chatton, in the process of his debate against Aureol's apparent being, analyzes the example of "seeing" something in a dream. ${ }^{29}$ According to Chatton, in such cases one does not see something non-existent (as allegedly Aureol claims), but something in the mental organ, which cannot be distinguished from, e.g., a vision of color. This explanation is not incongruous, because exactly the same thing happens in our experience of art: a picture is not a sensory vision of a real object, but it is perceived as such or substitutes for actual vision: e.g., when "someone sees a painted rose, this is not a vision of an [actual] rose, and yet he judges that he sees a rose" (Chatton 1989, p. 97.306-7). It is difficult not to see this statement as a sincere admission of the power of pictorial images that stems from real experience and is used to solve a difficult cognitive problem, as opposed to a mere case of using stock art examples from traditional symbolic theology. Chatton repeats the same example of perceiving a rose when he analyzes the difficult case of automatic neurocognitive reaction to certain shapes in our visual field, which even animals possess, e.g., when a sheep flees from something that is shaped like a wolf (even if it is not really a wolf, but, e.g., a sheep disguised as a wolf) ${ }^{30}$. As the case of a sheep fleeing from a sheep that looks like a wolf shows, such automatic reactions can also result in perceptual errors, which are brought forth to argue for or against the existence of the special mode of apparent being. This sort of perceptual reaction, Chatton explains, is not the same as intellectual judgment, but it is automatic, and therefore animals can have it, too. Chatton explains our automatic reaction as follows:

A rose... commonly has properties of a certain kind, such as red color and five-leaflet leaves, and so forth. Therefore, when someone, after having experienced these properties on many occasions, sees from afar something that has these properties, he immediately judges that this object is a rose, even though it may not be a [real] rose but something painted to resemble a rose. ${ }^{31}$

Wodeham, engaging some of Chatton's points, such as his attempt to account for visual illusions, repeats Chatton's example of perceiving a painted rose that is taken for a real one. In visual illusions,

27 Chatton, Rep. et Lect. 1, prol., qu. 4, a. 1 (Chatton 1989, p. 228.106-14), as quoted in Wodeham, Lectura secunda 1, dist. 1, qu. 2, par. 2, art. 1 (Wodeham 1990, pp. 211-12).

28 Aureol, Scriptum 1, d. 27, p. 2, art. 2, in The Peter Auriol Homepage (text version of 20 July 2009, copyright R.L. Friedman, http://www.peterauriol.net/auriol-pdf/SCR-27-2.pdf), p. 12.427-32.

29 Chatton, Rep. et Lect. 1, prol., q. 2, a. 2 (Chatton 1989, pp. 96-97).

30 The example goes back to Avicenna's passage from a version of his commentary on Aristotle's On the Soul, Part 6 (available in Latin in the 1200-1300's), which was widely used in medieval Latin scholastic literature. See Avicenna 1982.

31 Chatton, Rep. 1, dist. 3, q. 1, a. 2, ad 1, n. 41, in Chatton 2002, p. 219. 
some "concurrent species" are involved that are similar to an external thing seen previously, "and therefore a thing is believed to be seen, which nevertheless is not [truly] seen. But this creates no more difficulty than the case when someone believes that he is seeing a real rose while in fact he is seeing merely a painted rose" ${ }^{\prime 32}$. The implication for aesthetics and art of this identity of intentional appearances of things with the things themselves is that it removes the difference-at least the phenomenal difference- between the real thing and its phenomenal appearance-in the mode of apparent being, Aureol would say-potentially giving images, and thereby also artistic images, a status that is much higher than that of classic Platonic "imitation." Phenomenal appearances of things in fact feel like things themselves. And since such phenomenal appearances could be generated by painted images as well as real things, the difference between phenomenal experiences generated by real objects and artistic representations is diminished: both processes go through the same mechanism of creating a phenomenal picture-or the mode of apparent being, if we side with Aureol. It is clear that this important revelation about the nature of pictorial images comes, once again, not from a symbolic-theological way of thinking about art but from direct observation of actual images with a subsequent phenomenological analysis of the experience. It is also important that the images in the examples are not of an explicitly religious kind: roses, castles, emperors, greyhounds, and rabbits mentioned in theological examples are obviously part of secular chivalric imagery.

Two examples illustrate the new approach to art in the fourteenth century, when theologians begin to use mundane (i.e., secular) observations about art, including secular art, to make theological points, in this case to argue for or against the existence of the special kind of "apparent being" in the human perceptual system. Both examples are of everyday art that one would encounter in their day-to-day life, not specifically of symbolic religious art.

\section{The Example of Stained Glass}

One of the persistent examples in Franciscan theology in the fourteenth century is light passing through stained glass windows: to be sure, an actual daily experience for the religious at that time. Franciscans have been involved with stained glass and commented on it at least since the times of Bonaventure $^{33}$. Bonaventure himself mentions stained glass in the Narbonne Constitutions of the Franciscan Order produced in 1260 under his leadership and occasionally illustrates his theological points using the example of stained glass windows. However, he uses stained glass examples in exactly the same way as he uses iconic images: to make a point about the theological symbolism of the created world that points to the divine. Thus in the Collations on the Six Days of Creation (Collationes in Hexaemeron 12.14; $\mathrm{V}, 386 \mathrm{~b}$ ) Bonaventure uses stained glass symbolically to convince the reader of the existence of God's "exemplary reasons" (commonly known as divine ideas). There are several "aids for us to ascend to exemplary reasons". The first is "sensory creatures":

The entire world is a shadow, path, vestige, and the book written on the outside. For every creature contains a refulgence of the divine exemplar, even though it is mixed with darkness [there]; therefore, it is as if some opaqueness were mixed with light. Also, it is a path that leads one to the exemplar. Just as, from your observation, a ray [of sunlight] that enters through a [stained glass] window is colored in various ways according to the various colors of the different shards of [stained] glass, in the same way the divine ray shines in different ways in the various properties of individual creatures.

Stained glass continues to fascinate Franciscan theologians in the fourttenth century. However, the way they use the example of stained glass changes dramatically. Instead of merely pointing out

32 Wodeham, Lectura secunda 1, prol., qu. 3, par. 8 (Wodeham 1990, p. 81).

33 Thus Angela of Foligno records the presence of stained glass in the Basilica of St. Francis in Assisi in mid-thirteenth century: "I saw a stained-glass window depicting St. Francis being closely held by Christ" (Lachance 1993, p. 141). On Franciscans and stained glass see: Thompson 2016. 
some symbolism in a stock example, they seem to be mesmerized with their actual experience of colored light and draw on their actual observations-without any connection to existing theological positions-to make various points about human cognitive mechanisms. For example, Chatton and Wodeham's polemic against Aureol results in several sharp observations about the mechanism of sensory perception and phenomenal appearance as they attempt to explain away various perceptual examples that seem to suggest the existence of the special mode of apparent being. One such example relevant to aesthetics is the perception of a color patch on the wall or floor of a church after the sunlight has passed through a piece of stained glass in the church window. What exactly is the status of this observable patch of color? Is it the colored glass that we see? Is it the sun? Or is it just some redness? One of the examples in favor of the existence of apparent being has been that we experience afterimages after having seen a bright object, even after this object is no longer present. Rejecting Aureol's model of "apparent being", Wodeham sides with Chatton in affirming that afterimages are not as clear and not quite the same as when the object is actually in the line of sight. ${ }^{34} \mathrm{He}$ attributes these afterimages to the impact of the residual sensory form (species) in the mind, which does not create the same sort of clarity as the presence of an actual object of vision. Re-examining the example of light passing through a stained glass window used by Ockham and Chatton, Wodeham observes that "the fact that I see redness that is produced on the wall from the passing of the ray of the sun through red [stained] glass does not make me conclude that I see the glass but only that I see that redness". This is exactly what happens when we experience afterimages: we see residual sensory species of sensory objects, not objects themselves (Wodeham 1990, p. 76). What allows us to avoid perceptual error in this case is the fact that, in addition to detecting color and shape, our vision also includes situational awareness, in this case the perception that there is no direct line of sight to the object of vision, which saves us from the error of "seeing" the original object in the case of an afterimage. Our vision takes into consideration the position of the body vis-à-vis the object:

Now what one sees there is the species, namely, the redness that is caused by the passing ray of light, and the redness of the glass does not appear to me on this account. For this reason one can make an argument that it also does not appear to me in another situation [i.e., when there is a direct line of sight to the primary object] that I see the principal thing merely because I see its species, but that something else [here] is added to the cause [of the apparition], let's say a powerful image of that principal thing in the imagination that concurs [with the species]. However, no such thing concurs [with the species] in this case [when there is no direct line of sight to the object of vision], and therefore it does not appear to me that I see the glass. Indeed, what prevents the error of [perceptual] judgment in this case is that, with only the species being present, the [physical] position [of the observer], which is out of alignment with the principal object of vision, blocks the direct line of sight, and therefore [also blocks] the [formation of the] image in the imagination [from that principal object of vision]. ${ }^{35}$

The example of light passing through a stained glass window, of course, can be interpreted in the opposite way: seeing redness on the wall does alert us both to the existence of a stained glass window and to the fact that the sun is out. However, it is the fact itself that Franciscan theologians make fine conceptual points using an analysis of an actual aesthetic experience of an art object that is important here.

34 Wodeham, Lectura secunda 1, prol., qu. 3, par. 7 (Wodeham 1990, p. 75).

35 Wodeham, Lectura secunda 1, prol., qu. 3, par. 8 (Wodeham 1990, p. 78). 


\section{The Example of the Image of the Emperor}

Fourteenth-century Franciscans are equally keen on using examples of painted images, of the type they must have observed in the form of frescoes on walls of buildings. It is important that the example discussed below is not of a religious, but of a secular image, perhaps seen in a palace. The example is used in the discussion about the status of pictorial representations, which is part of the discussion of "apparent" or "intentional" being among Franciscan theologians. Both Aureol and Wodeham bring up the artistic-aesthetic example of the depiction of the emperor on the wall, which appears as early as in the writings of Scotus's secretary William of Alnwick ${ }^{36}$. Each uses the example in defense of his own theory: Aureol in defense of apparent being and Wodeham against this model. Aureol must defend his theory against the opinion that phenomenal appearances give no more being to their objects than an image of the emperor on the wall gives to the emperor. He describes the opinion as follows: "a thing conceived [by the mind] only receives its name from the act of the intellect and does not acquire any intentional being, any more than the emperor acquires [any being] from his depiction if he is painted" ${ }^{\prime 37}$. Wodeham is one of the theologians who support this opposing opinion. His point is that "the emperor" in the picture is just a metaphorical denomination, because one only deals with the real emperor when one is in contact with the real object of perception, a real person in this case:

an extramental thing, whether it exists or not, has no being whatsoever by virtue of being cognitively perceived-neither in the mind nor outside the mind, and neither in a qualified sense nor in a non-qualified sense-just as neither does the emperor have any being whatsoever by virtue of being painted... However, in both cases-when the emperor is referred to as painted or an object of cognition is referred to as cognized-something (the emperor or the object of cognition) receives its external name from something else (picture or cognitive act). ${ }^{38}$

For "the emperor to be depicted" amounts to nothing more than the "existence of a picture which was created for the purpose of reminding us of the emperor" (Wodeham 1990, pp. 89-90).

Although Aureol disagrees with the position that equates the status of phenomenal appearance with the status of depicted images of objects, in his debates against this objection he does not disagree with the assessment of painted images as inferior to mental representations. Indeed,

[for a thing] to receive one's name from something does not amount to being present or manifest to the thing that gives this [original thing] its name, nor to be observed by it, nor to be in its line of sight, nor to occur to it, nor to be placed over and against it-just as it is clear that if the emperor is painted, [the emperor] is not present or manifest to the picture [or the wall], nor is observed by it, nor is in its line of sight, nor occurs to it, nor is placed over and against it. However, our experience teaches us that if a thing is cognitively perceived, it is manifest and present to the intellect that perceives it, and occurs to it, is observed by it, and is in its line of sight. Therefore, it not only receives its name [from the phenomenal apparition] but also some intentional being. ${ }^{39}$

36 Cf. Perler 2001, p. 220.

7 Scriptum 1, d. 23, a. 2, in Pinborg 1980, p. 135; my italics.

38 Lectura secunda 1, prol., qu. 4, par. 3 (Wodeham 1990, pp. 89-90).

39 Petrus Aureoli, Scriptum 1, d. 23, a. 2, in Pinborg 1980, p. 136. The same example is repeated in Scriptum 1, d. 27, p. 2, art. 2, in The Peter Auriol Homepage, p. 11.395-6, and in the answer to the 4th objection, The Peter Auriol Homepage, p. 16.572-75, 81-82: a thing that is understood does not receive merely its name in the process of intellection, "as the emperor from a painting [of him] or something represented [in a picture] from its representation: for the emperor himself is not present to the wall through a picture [of him], nor is he placed over and against it, nor does [the wall] judge about him [variant: about his existence], unlike things that are present to the intellect [in phenomenal apparitions]... and yet every one who uses his intellect experiences a thing present to his intellect, when he thinks about it; therefore this sort of being [i.e., intentional] does not amount to receiving a name". Also cf. Scriptum 1, d. 35, q. 1, a. 1, in The Peter Auriol Homepage, 11. 326-36: "Similarly, if the emperor painted on a wall appeared [phenomenally] to the wall through a picture [of him] painted on this wall, one could say that this wall would be cognitively aware of the painted emperor". 
Now both Wodeham in opposing Aureol, and Aureol in defending against this specific point-namely that an image or depiction of something does not make that thing present to the medium where it is depicted, while when we intellectually or sensorily perceive something, the thing itself is present to our mind-miss the point of artistic representations, formerly attested to by Chatton and Wodeham himself, namely that they make things appear to $u s$, not to the medium. Aureol, however, corrects the situation elsewhere, ascertaining the real purpose of images, when he uses the example of the depiction of the emperor to support his theory that there is some mental substrate underlying our phenomenal pictures, even though it is not perceived as such, but creates an impression of extramental things being present to $\mathrm{us}^{40}$. It is the same with pictorial representations:

a real picture relates to [giving] depicted being [to something] in the same way as a real [phenomenal] apparition relates to giving apparent being [to something]. However, the emperor would never acquire depicted being except insofar as there is some real picture [of him]. Therefore, nor will [real] things appear to the intellect except insofar as there are some formal and real apparitions [of them] in the intellect (The Peter Auriol Homepage, 11. 370-3).

As such the purpose of pictorial representations is different: just as in the case of a special kind of mental substrate that makes a thing appear to us phenomenally, a picture makes a thing or a person appear to us as well. In the absence of pictures, we would merely have abstract thoughts about persons and things, not their "presential" (Aureol's term) perception.

No matter what the particular claims of Franciscan theologians are, their discussion reveals something fundamental about the status of the artistic image, as well as, generally, the status of the phenomenal. Wodeham's point is that "the emperor" in the picture is just a metaphorical denomination, because one only deals with the real emperor when one is in contact with the real person. However, Aureol would say that our experience of "real" things from the point of view of the mental mechanisms involved is not all that different from our experience of images: in either case all we see is an apparent being (ens visum or manifestum). Artistic images thus cannot be regarded by default as a "lower" form of delivering phenomenal experience. In fact, even Chatton and Wodeham admit that a picture of an object or a person can create an impression of a real presence of an object or a person through the image, as in the example of a painted rose above. In other words, contact through a picture does not have to be less real than contact through a sense perception of a "real object," because both processes ultimately result in phenomenal appearances (or "apparent being," according to Aureol).

\section{Secularization of Art?}

It is becoming abundantly clear, then, that while Bonaventure's understanding of the role of artistic images, artifacts, and aesthetic experience in the thirteenth century remains squarely within the realm of symbolic theology or the Patristic theology of the icon, new cognitive models in the Franciscan psychology and philosophy of perception in the fourteenth century begin to rely on the actual experience of artifacts and images for new insights. Thus in the fourteenth century, art in theology is no longer used as sacred or symbolic, but in a "secular" fashion: as arousing one's intellectual wonder and curiosity. Instead of sacred symbols, artistic images and artifacts turn into contemplative tools. One can only wonder whether this attitude was inspired by the new style in art, such as that of Giotto's increased realism, or shepherded this style, to turn art into a meditative tool to wonder at and draw insights, instead of using it symbolically to direct our mental gaze at the prototype, while ignoring all the intricacies of the sensory perception of the actual art object in front of us. This wonder at the sight of an artistic image (which mysteriously makes objects appear before

40 Scriptum 1, d. 9, q. 1. a. 1, in The Peter Auriol Homepage, 11. 364-9: "A thing cannot possess an apparent being of this kind except by virtue of some real absolute [substrate] that exists in the intellect." 
our mental gaze and makes us think about cognitive mechanisms) or at the play of colored light in a cathedral (which makes us wonder about the mysteries of sensory perception), to be sure, is used in theological discourse about the divine. But the inspiration for this discourse is no longer merely scriptures and sacred symbols, but also our sensory and cognitive experiences of this reality, which is produced by the power of both God and art.

Funding: This research received no external funding.

Conflicts of Interest: The author declares no conflict of interest.

\section{References}

Attfield, Robin. 2018. Wonder, Value, and God. London and New York: Routledge.

Aureoli, Peter. 1956. Scriptum Super Primum Sententiarum. Edited by Eligius M. Buytaert. St. Bonaventure: The Franciscan Institute, vol. 1.

Avicenna. 1982. Kitāb al-Najāt. Edited by Majid Fakhry. Beirut: dār al-‘āāāq al-jadīda.

Bychkov, Oleg. 2010. Aesthetic Revelation: Reading Ancient and Medieval Texts after Hans Urs von Balthasar. Washington: Catholic University of America Press.

Bychkov, Oleg. 2013. The Place of Aesthetics and the Arts in Medieval Franciscan Theology. In Beyond the Text: Franciscan Art and the Construction of Religion. Edited by Xavier Seubert and Oleg Bychkov. St. Bonaventure: Franciscan Institute Publications, pp. 196-209.

Bychkov, Oleg. 2014. 'But Everyone Experiences the Opposite': John Duns Scotus's Aesthetic Defense of Anselm's "Proof" of the Existence of God in Light of Present-day Thought. Franciscan Studies 72: 259-303. [CrossRef]

Bychkov, Oleg. 2015. "Metaphysics as Aesthetics": Aquinas' Metaphysics in Present-day Theological Aesthetics. Modern Theology 31: 147-78. [CrossRef]

Bychkov, Oleg. 2018. The Status of the Phenomenal Appearance of the Sensory in Fourteenth-century Franciscan Thought after Duns Scotus (Peter Aureol to Adam of Wodeham). Franciscan Studies 76: 267-85. [CrossRef]

Chatton, Walter. 1989. Reportatio et Lectura super Sententias: Collatio ad Librum Primum et Prologus. Edited by Joseph C. Wey. Toronto: Pontifical Institute of Mediaeval Studies.

Chatton, Walter. 2002. Reportatio super Sententias. Edited by Joseph C. Wey and Girard J. Etzkorn. Liber I, Distinctiones 1-9. Toronto: Pontifical Institute of Mediaeval Studies.

Costa, Paolo. 2011. A Secular Wonder. In The Joy of Secularism: 11 Essays for How We Live Now. Edited by George Levine. Princeton: Princeton UP, pp. 134-54.

Denifle, Heinrich, and Emile Châtelain, eds. 1889. Chartularium Universitatis Parisiensis. Paris: Delalain Bros, vol. 1.

Eagleman, David. 2011. Incognito: The Secret Lives of the Brain. Edinburgh, London, New York and Melbourne: Canongate Books.

Eagleman, David. 2017. The Brain: The Story of You. New York: Vintage Books.

Evdokimov, Paul. 1996. The Art of the Icon: A Theology of Beauty. Redondo Beach: Oakwood Publications.

Lachance, Paul, ed. 1993. Angela of Foligno. New York: Paulist Press.

Levine, George, ed. 2011. The Joy of Secularism: 11 Essays for How We Live Now. Princeton: Princeton UP.

Ockham, William. 1967. Guillelmi de Ockham Scriptum in librum primum Sententiarum. Ordinatio. Opera Theologica 1. Edited by Gedeon Gál and Stephen Brown. St. Bonaventure: The Franciscan Institute.

Olivi, Petrus Iohannis. 1924. Quaestiones in Secundum Librum Sententiarum. Edited by Bernhard Jansen. Quaracchi: Typographia Collegii S. Bonaventurae, vol. 2.

Perler, Dominik. 2001. What Are Intentional Objects? A Controversy Among Early Scotists. In Ancient and Medieval Theories of Intentionality, idem ed. Leiden, Boston and Köln: Brill, pp. 203-26.

Pinborg, Jan. 1980. Radulphus Brito on Universals. Cahiers de L'Institut du Moyen-Âge grec et Latin 35: 133-37.

Quenot, Michel. 1996. The Icon: Window on the Kingdom. Crestwood: St. Vladimir's Seminary Press.

Sendler, Egon. 1999. The Icon: Image of the Invisible. Elements of Theology, Aesthetics and Technique. Redondo Beach: Oakwood Publications.

Taylor, Charles. 2011. Disenchantment-Reenchantment. In The Joy of Secularism: 11 Essays for How We Live Now. Edited by George Levine. Princeton: Princeton UP, pp. 57-73. 
Thompson, Nancy. 2016. The Franciscans and Stained Glass in Tuscany and Umbria. In Mendicant Cultures in the Medieval and Early Modern World: Word, Deed, Image. Edited by Sally J. Cornelison, Nirit Ben-Aryeh Debby and Peter Francis Howar. Turnhout: Brepols, pp. 22-44.

Vasalou, Sophia. 2015. Wonder: A Grammar. Albany: SUNY Press.

Warner, Michael, Jonathan VanAntwerpen, and Craig Calhoun, eds. 2010. Varieties of Secularism in a Secular Age. Cambridge: Harvard UP.

Willmott, Glenn. 2018. Reading for Wonder: Ecology, Ethics, Enchantments. Cham: Palgrave Macmillan.

Wodeham, Adam. 1990. Lectura secunda in Librum Primum Sententiarum. Prologus et Distinctio Prima. Edited by Rega Wood and Gedeon Gál. St. Bonaventure: St. Bonaventure University. 